\title{
ESTRATÉGIAS PARA O DESENVOLVIMENTO DE NOVAS CULTIVARES DE MANGUEIRA PARA O SEMIÁRIDO BRASILEIRO ${ }^{1}$
}

\section{CARLOS ANTONIO FERNANDES SANTOS ${ }^{2}$, JOSÉ MOACIR PINHEIRO LIMA FILHO², FRANCISCO PINHEIRO LIMA NETO ${ }^{2}$}

RESUMO - A mangueira é uma das principais fruteiras comerciais no Semiárido brasileiro, sendo que a cultivar Tommy Atkins ocupa $85 \%$ da área total cultivada com a cultura. O objetivo deste trabalho foi avaliar o emprego de estratégias para reduzir o período juvenil e as trabalhosas polinizações manuais em mangueira, de forma a acelerar o desenvolvimento de novas cultivares da espécie para o Semiárido brasileiro. Foram identificadas plantas isoladas das cultivares Haden e Espada dentro de plantios comerciais da cultivar Tommy Atkins, numa fazenda exportadora de manga, em Petrolina-PE. Mudas das progênies foram transplantadas com seis meses de idade para o campo. O manejo para a indução floral foi realizado com poda, controle da irrigação e aplicação de Paclobutrazol e nitrato de potássio. O DNA extraído das progênies e parentais foi submetido a análises com marcadores microssatélites publicados para Mangifera indica $\mathrm{L}$. O manejo combinado foi eficiente para induzir a floração e a frutificação em, aproximadamente, $70 \%$ das progênies após dois anos e meio de transplantio. Dos 94 indivíduos analisados com três microssatélites, 83\% foram identificados como híbridos entre 'Haden' x 'T. Atkins'. Dos 401 indivíduos analisados com um microssatélite, $10 \%$ foram identificados como híbridos entre 'Espada' $x$ 'T. Atkins'. A estratégia adotada foi eficiente para reduzir o período juvenil e evitar os trabalhosos cruzamentos manuais em mangueira, sendo que o desenvolvimento de novas cultivares da espécie para a região pode ser concluído com oito a dez anos, incluindo as rigorosas avaliações agronômicas.

Termos para indexação: Mangifera indica, microssatélites, melhoramento, PBZ.

\section{MANGO STRATEGIES TO DEVELOP NEW VARIETIES TO THE BRAZILIAN TROPICAL SEMI-ARID REGION}

\begin{abstract}
Mango is one of the most important fruit crop in the Brazilian Semi-Arid region. The cultivar Tommy Atkins has been grown in $85 \%$ of total area dedicated to this crop. The goal of this research was to evaluate strategies to reduce the juvenile period and to replace the laborious hand pollinization in order to accelerate the development of mango new cultivars to the region. Isolated plants of 'Haden' and 'Espada' were identified within a commercial orchards established with "Tommy Atkins' in a farm dedicated to export mangoes in Petrolina, PE, Brazil. Seedlings with six months old were transplanted to field. Floral and fruit setting were accomplished with pruning, irrigation management, application of paclobutrazol and potassium nitrate. The DNA extracted from progenies and parentals was analyzed for Mangifera indica published microsatellites. The combined management was efficient to induce flowering and fruit setting in, approximately, $70 \%$ of the progenies, after two year and half of field establishment. Among ninety-four individuals analyzed with three microsatellites $83 \%$ were identified as true hybrids of 'Haden' $x$ 'T. Atkins'. Among four hundred and one individuals analyzed with only one microsatellite $10 \%$ were identified as true hybrids of 'Espada' $x$ 'T. Atkins'. The adopted strategies were efficient to reduce the juvenile period and the laborious hand crossing in mango. It was estimated that the development of new mango cultivars could be accomplished with eight to ten years of work, including the complex agronomic evaluations.
\end{abstract}

Index terms: Mangifera indica, microsatelites, breeding, PBZ.

${ }^{1}$ (Trabalho 130-09). Recebido em: 27-05-2009. Aceito para publicaçaõ em: 22-01-2010. Apoio financeiro da FACEPE.

${ }^{2}$ Embrapa Semi-Árido. Caixa Postal 23. 56302-970. Petrolina, PE. Brasil. E-mail: casantos@cpatsa.embrapa.br; zemoa5@hotmail.com; pinheiro.neto@cpatsa.embrapa.br 


\section{INTRODUÇÃO}

O melhoramento da mangueira (Mangifera indica L.) é dificultado pelo longo período juvenil, pela poliembrionia nos tipos originários do sudeste da Ásia e ausência de variabilidade no germoplasma de muitos países produtores de manga. $\mathrm{O}$ avanço mais significativo no desenvolvimento de cultivares de mangueira ocorreu com as introduções e seleções dentro de progênies resultantes de polinização aberta no sul da Flórida-EUA, de tal forma que a região passou a ser considerada como um centro secundário de diversidade genética da espécie (LITZ; GÓMEZLIM, 2005). As cultivares de mangueira desenvolvidas na Flórida são a base dos sistemas de cultivo voltados para exportação em muitos países do mundo (SCHNELL et al., 2006). No Semiárido brasileiro, a cultivar floridiana 'Tommy Atkins' é cultivada em $85 \%$ de uma área total superior a 25.000 ha ocupada com mangueiras (ANUÁRIO BRASILEIRO DA FRUTICULTURA, 2006).

Fatores como alto nível de heterozigose, dificuldade em fazer polinizações controladas e alto custo e tempo envolvido para avaliar um grande número de progênies interferem não só no desenvolvimento de novas cultivares, como também em estudos de herança genética de muitos caracteres da espécie (LITZ; GÓMEZ-LIM, 2005). A possibilidade de propagar vegetativamente indivíduos resultantes de polinização aberta com características superiores é uma vantagem da mangueira que tem sido explorada no desenvolvimento de novas cultivares (IYER; DEGANI, 1997). Polinizações controladas têm sido empregadas mais recentemente para o desenvolvimento de novas cultivares de mangueira (PINTO et al., 2002a).

O objetivo deste trabalho foi avaliar o estabelecimento de progênies oriundas de polinização aberta de plantas isoladas de 'Haden' ou 'Espada' dentro de áreas comerciais exclusivas de 'Tommy Atkins', associando ao manejo e aplicação de reguladores vegetais, de forma a acelerar o desenvolvimento de novas cultivares de mangueira para o Semiárido brasileiro.

\section{MATERIAL E MÉTODOS}

Obtenção e manejo das progênies: foram identificadas plantas isoladas das cultivares Haden e Espada dentro de plantios comerciais da cultivar Tommy Atkins, numa fazenda exportadora de manga, em Petrolina-PE. Foram colhidos frutos da planta de 'Haden' ou 'Espada' dentro da área da 'Tommy Atkins', considerando a distância mínima de 200 m em relação a outras cultivares que não a 'Tommy Atkins', para evitarem-se outros tipos de cruzamentos. Mudas das progênies de 'Haden' ou 'Espada' foram transplantadas com seis meses de idade para o campo, no espaçamento de 4 m x 4 m, na Estação Experimental de Mandacaru, da Embrapa Semiárido, localizada em Juazeiro-BA. O sistema de irrigação adotado foi por microaspersão, e as adubações foram realizadas conforme análises dos solos.

Podas de formação foram realizadas conforme práticas da região, sendo que após dois anos do transplantio para o campo foi aplicado, em cada planta, $1 \mathrm{~g} / \mathrm{m}$ do regulador vegetal paclobutrazol (PBZ) por metro linear do diâmetro da copa. Foram realizadas pulverizações com nitrato de potássio a $2 \%$ até a emissão de inflorescências nas progênies.

Extração de DNA e reações de microssatélites: O DNA foi extraído das folhas usando o protocolo CTAB 2x de Doyle e Doyle (1990), modificado para: 6.000 e $10.000 \mathrm{rpm}$ na primeira e na segunda centrifugação, respectivamente; betamercaptoetanol a $2 \%$ e incubação a $60^{\circ} \mathrm{C}$ durante 30 minutos para todas as amostras. Após a adição do tampão TrisEDTA, a solução de DNA foi tratada com RNAse para remover RNAs coisolados. A quantificação e a análise de integridade do DNA foram realizadas em gel de agarose a $0,8 \%$, seguido de armazenamento das amostras de DNA a $-20^{\circ} \mathrm{C}$. O DNA genômico foi diluído para $30 \mathrm{ng} / \mathrm{mL}$.

Avaliação inicial com os parentais 'Haden' e 'Tommy Atkins' e 'Espada' e 'Tommy Atkins' foi realizada, utilizando-se 30 primers microssatélites de Mangifera indica desenvolvidos e publicados por Duval et al. (2005). As reações de amplificação foram feitas em um volume total de $20 \mu \mathrm{L}$, contendo 30 ng de DNA genômico, 1x de Tampão para Taq DNA Polimerase, 2,0 mM MgCl , 0,2 $\mathrm{mM}$ de dNTPs, 0,2 $\mu \mathrm{M}$ de cada primer, 0,15 Unidades da enzima Taq DNA Polimerase. O programa PCR consistiu em um ciclo de desnaturação a $94^{\circ} \mathrm{C}$, por 4 min, seguido de 32 ciclos a $94^{\circ} \mathrm{C}$, por $45 \mathrm{~s}, 55^{\circ} \mathrm{C}$ por $60 \mathrm{~s} \mathrm{e} 72^{\circ} \mathrm{C}$ por $60 \mathrm{~s}$ e uma etapa de extensão final a $72^{\circ} \mathrm{C}$, por 4 min. Após a amplificação, os fragmentos foram visualizados por meio de eletroforese em gel de poliacrilamida corado com nitrato de prata, conforme descrito por Creste et al. (2001). Microssatélites que apresentavam um alelo na 'T. Atkins' e ausência do alelo na 'Haden' foram selecionados para genotipagem das progênies. Foram consideradas como progênies híbridas aquelas que possuíam o alelo proveniente da 'Tommy Atkins' que não era comum na 'Haden', ou seja, presença na progênie do alelo exclusivo da 'Tommy Atkins'.

Para a progênie 'Espada' x 'T. Atkins', foi 
realizada a identificação fenotípica inicial para diversos caracteres, como formato de folha e cor e formato do fruto, sendo que apenas um grupo de plantas considerado híbrido e outro grupo de plantas originadas de autofecundações ou originadas de embriões nucelares (planta e fruto típico da 'Espada') foram genotipados com microssatélites.

\section{RESULTADOS E DISCUSSÃO}

Foram estabelecidas no campo 94 progênies do provável cruzamento de 'Haden' $\mathrm{x}$ 'Tommy Atkins' e 401 do provável cruzamento de 'Espada' x 'Tommy Atkins'. O manejo de poda, aplicação de PBZ e nitrato de potássio foram eficientes para induzir a floração e a frutificação em aproximadamente $70 \%$ das progênies após dois anos e meio de transplantio. Segundo Iyer e Degani (1997), mudas de mangueira demoram entre três e 10 anos para iniciarem a produção de frutos. Ainda segundo esses mesmos autores, diversos métodos têm sido sugeridos para reduzir o período juvenil na espécie, entre os quais a enxertia de plantas jovens resultantes de cruzamentos em porta-enxerto no início do florescimento. A estratégia de associar manejo com PBZ e nitrato de potássio, usado de forma pioneira neste trabalho, foi eficiente para reduzir o período juvenil sem as trabalhosas atividades para realização de enxertia.

A associação do manejo de poda, irrigação, PBZ e nitrato de potássio têm sido usada em larga escala na região do Vale do São Francisco em plantios comerciais (ALBUQUERQUE et al., 2002), visando principalmente à produção de frutos para a exportação, sem que tenha, até o momento, ocorrido relatos de alteração no padrão e na qualidade do fruto. Iyer e Degani (1997), citando fontes anônimas, relatam que a indução química do florescimento pode alterar o tamanho dos frutos, o que poderia induzir a erros no momento da seleção de progênies. Nas caracterizações pós-colheita efetuadas nos frutos de várias progênies do provável cruzamento 'Haden' $x$ 'Tommy Atkins', foram observados frutos com tamanhos normais, similares aos dos parentais.

Os microssatélites mMiCIR005, mMiCIR030 e mMiCIR036 foram selecionados para genotipagem de 94 indivíduos de 'Haden' x 'T. Atkins', pois apresentaram um alelo presente na 'T. Atkins' e ausência na 'Haden' (Figura 1). Um dos alelos da 'Haden' em cada um dos três microssatélites sempre esteve presente na 'T. Atkins', pois a 'Haden' é a planta-materna que originou a 'T. Atkins' (Schnell et al., 2006). Apenas o mMiCIR036 apresentou situação típica de retrocruzamento, onde a planta-mãe 'Haden' é homozigota e sua descendência 'T. Atkins' é hete- rozigota (Figura 1-C). Os outros dois microssatélites foram heterozigotos nos dois parentais (Figura 1-A e 1-B), reforçando a alta heterozigose presente em fruteiras, de modo geral.

Dos 94 indivíduos analisados com os três microssatélites, 78 foram identificados como híbridos entre 'Haden' $x$ 'T. Atkins', pois pelo menos um dos alelos da 'T. Atkins' estava presente na progênie (Figura 1). Esse valor (78/94) corresponde a 83\% de obtenção de híbridos com a estratégia adotada de coletar frutos numa planta isolada de 'Haden' circundada por plantas de 'T. Atkins' em plantios comerciais. Deve ser destacado que não foi observado nenhum 'contaminante', ou seja, indivíduo polinizado por outra variedade que não 'T. Atkins', pois o padrão de alelos observado foi consistente para todos os indivíduos para os três microssatélites (Figura 1).

No cruzamento 'Espada' x 'T. Atkins', apenas o microssatélite mMiCIR002 foi suficiente para separar os híbridos dos produtos de autofecundação ou de origem nucelar, pois apresentou diferentes alelos em homozigose em cada um dos parentais (Figura 2). Os indivíduos identificados no campo como produtos de autofecundação ou de origem nucelar apresentaram apenas o alelo da 'Espada', enquanto os identificados no campo como híbridos apresentaram os alelos provenientes dos dois parentais.

Os três microssatélites empregados na progênie 'Haden' x 'T. Atkins' possibilitaram a identificação de híbridos em $91 \%$ dos casos, sendo que indivíduos como 1; 10; 12; 17 e 28 (Figura 1) não podem ser considerados como produtos de autofecundações, pois é necessário o uso de maior número de microssatélites para confirmar ou excluir essa possibilidade. Foram identificadas três autofecundações no cruzamento 'Haden' $x$ 'T. Atkins', entre os quais o individuo 40 (Figura 1), pois apresentavam alelos exclusivos da planta-materna. Os microssatélites empregados neste trabalho, tanto para 'Haden' $\mathrm{x}$ ' $\mathrm{T}$. Atkins' como para 'Espada' x 'T. Atkins', podem ser usados para dirimir dúvida de autenticidade em disputas comerciais, pois apresentaram padrão exclusivo de alelos na genotipagem (Figura 1 e Figura 2).

Pinto (1995) relatou índices de sucesso variando de 0,79 a $8,20 \%$ com a adoção de técnicas tradicionais de hibridação controlada em mangueira, que consiste na proteção da planta feminina com telados, emasculação de flores e polinização com pólen da planta masculina. Pinto (1995), contudo, não relata a comprovação dos híbridos, seja por marcador fenotípico, seja por marcador molecular. Os percentuais de sucesso de híbridos obtidos neste trabalho, de $83 \%$ para 'Haden' x 'T. Atkins' e de $10 \%$ 
para 'Espada' x 'T. Atkins', são bastante superiores aos relatados por Pinto (1995), especialmente para o cruzamento 'Haden' $x$ 'T. Atkins'. O alto percentual observado no cruzamento 'Haden' $x$ 'T. Atkins' deve estar associado com o sincronismo na floração observado entre os dois parentais, enquanto no cruzamento 'Espada' x 'T. Atkins' foi observado um índice em torno de $10 \%$ de sucesso de hibridação, o que pode ser atribuído à ausência de sincronismo entre os dois parentais observada no campo. Outra explicação para o baixo índice de híbridos no cruzamento 'Espada' x 'T. Atkins' é a poliembrionia exibida pela 'Espada', que pode favorecer os vários indivíduos de origem materna na formação da muda.

Na região do semiárido brasileiro, a 'Espada' é usada como porta-enxerto para o estabelecimento de plantios comerciais de mangueira, devido a sua rusticidade e poliembrionia (PINTO et al., 2002b). Dessa forma, a presença de plantas adultas em plantios comerciais de 'T. Atkins' pode ser observada com frequência devido à morte do enxerto ou mesmo à presença de algum broto 'ladrão' não eliminado. A presença da 'Haden' em plantios comerciais de 'T. Atkins' pode ser atribuída a misturas ou erros na produção das mudas, como observado no plantio comercial, onde foram coletados os frutos da 'Haden' deste trabalho.

No presente estudo, um dos parentais utilizados foi sempre a 'T. Atkins', pois o objetivo do programa de melhoramento da mangueira na Embrapa Semiárido é o desenvolvimento de cultivares que combinem os pontos positivos desta cultivar como aceitação no mercado internacional, tolerância à antracnose e resistência ao transporte, associados às outras características presentes em outras cultivares, como porte da planta, ausência do colapso interno e sabor.

Outras opções que podem ser adotadas com a estratégia do presente estudo podem ser: 1 . Poda para redução da copa de plantas adultas de diferentes cultivares adjacentes no campo, construção de telados para proteção das mesmas, colocação de pupas de Musca domestica ou adultos de Apis mellifera, que, segundo Siqueira et al. (2008), são agentes polinizadores eficientes para a mangueira, visando à obtenção de frutos para produção de híbridos e posterior genotipagem com microssatélites disponíveis na literatura (DUVAL et al., 2005; SCHNELL et al. 2005), e 2. Substituição da copa, por sobre-enxertia, de uma única planta, numa área exclusiva de uma cultivar por outra cultivar diferente, visando à produção de frutos e genotipagem de progênies com microssatélites. Mesmo nesta última situação, a grande produção de frutos híbridos é mais vantajosa que as técnicas descritas por Pinto (1995). Para estudos genéticos, como desenvolvimento de mapas de ligações genéticas e mapeamento de QTLs, a existência de populações de tamanho superior a 150 indivíduos é necessária para a maioria das situações (LIU, 1998).

Os resultados obtidos neste trabalho, associando manejo de poda, irrigação, aplicação de PBZ e nitrato de potássio com a colheita de frutos de plantas de diferentes cultivares dentro de plantios comerciais de 'T. Atkins', são bastante animadores, pois indicam que é possível reduzir significativamente o período juvenil da mangueira no semiárido brasileiro. Combinado com a clonagem dos indivíduos superiores, possível na maioria das fruteiras, o melhoramento da mangueira passa a ter o mesmo tempo que uma espécie anual que normalmente requer de oito a dez anos, incluindo as rigorosas avaliações agronômicas.

TA HA $1 \quad 3 \quad 4 \quad 5 \quad 6 \quad 7 \quad 91011121314151718192021222324252627282930313233343738 \quad 39404143444647485153545556$

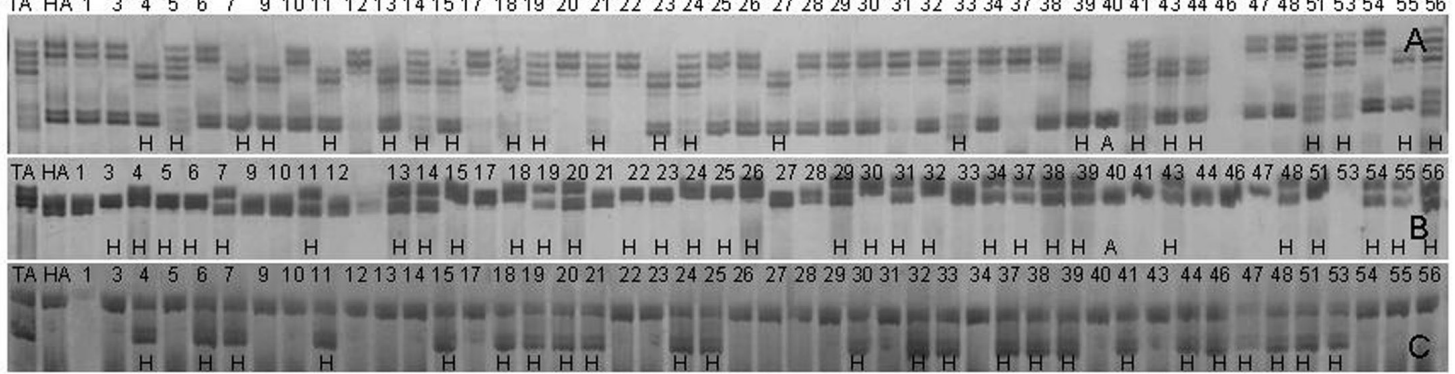

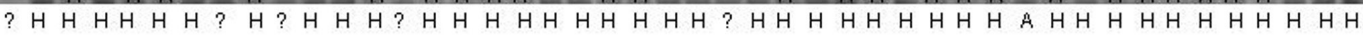

FIGURA 1 - Gel de poliacrilamida 6\% com 46 indivíduos do cruzamento 'Haden' (HA) x 'Tommy Atkins' (TA) genotipados com os microssatélites mMiCIR005 (painel A), mMiCIR030 (painel B) e mMiCIR036 (painel C). H=híbrido, A=autofecundação e ?=pode ser autofecundação ou híbrido. 


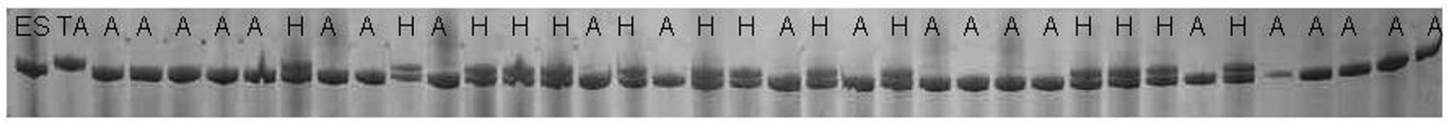

FIGURA 2 - Gel de poliacrilamida 6\% com 36 indivíduos do cruzamento 'Espada' (ES) x 'Tommy Atkins' (TA) genotipados com o microssatélite mMiCIR002. H=híbrido e A=autofecundação ou de origem nucelar.

\section{CONCLUSÕES}

1-A combinação de manejo de poda, aplicação de paclobutrazol e nitrato de potássio é eficiente para induzir a floração e a frutificação em aproximadamente $70 \%$ das progênies de 'Haden' $x$ 'Tommy Atkins' e 'Espada' $x$ ‘Tommy Atkins', após dois anos e meio de transplantio.

2-Dos 94 indivíduos analisados com três microssatélites, $83 \%$ são identificados como híbridos entre 'Haden' x 'T. Atkins', enquanto dos 401 indivíduos analisados com um microssatélite, $10 \%$ são identificados como híbridos de 'Espada' x 'T. Atkins'.

\section{REFERÊNCIAS}

ALBUQUERQUE, J.A.S. de; MEDINA, V.D.; MOUCO, M.A. do C. Indução Floral. In: GENÚ, P.J.de C.; PINTO, A.C. de Q. (Ed.). A cultura da mangueira. Brasília: Embrapa Informação Tecnológica, 2002. p. $259-276$.

ANUÁRIO BRASILEIRO DA FRUTICULTURA 2006. Santa Cruz do Sul: Editora Gazeta Santa Cruz, 2006. $136 \mathrm{p}$.

CRESTE, S.; TULMANN NETO, A.; FIGUEIRA, A. Detection of single sequence repeat polymorphisms in denaturing polyacrylamide sequencing gels by silver staining. Plant Molecular Biology Reporter, New York, v. 9, p. 299-306, 2001.

DOYLE, J.J.; DOYLE, J.L. Isolation of plant DNA from fresh tissue. Focus, Ithaca, v.12, p. 13-15, 1990.

DUVAL, M.F.; BUNEL J.; SITBON, C.; RISTERUCCI, A.M. Development of microsatellite markers for mango (Mangifera indica L.). Molecular Ecology Notes, Oxford, v. 5, p. 824-826, 2005.

IYER, C.P.A.; DEGANI, C. Classical breeding and genetics. In: LITZ, R.E. (Ed.). The mango: botany, production and uses. Wallingford: CAB International, 1997. p. 49-68.
LITZ, R.E.; GÓMEZ-LIM, M.A. Mangifera indica Mango. In: LITZ, RE (Ed.). Biotechnology of fruit and nut crops. Wallingford: $\mathrm{CAB}$ International, 2005. p. 41-61.

LIU, B.H. Statistical Genomics: linkage, mapping, and QTL analysis. Boca Raton: CRC Press, 1998. $650 \mathrm{p}$.

PINTO, A.C. de Q. Melhoramento da mangueira (Mangifera indica L.) no ecossistema dos cerrados do Brasil Central por meio de hibridação. Pesquisa Agropecuária Brasileira, Brasília, v.30, p. 369374, 1995.

PINTO, A.C. de Q.; SOUZA, V.A.B. de; ROSSETTO, C.J.; FERREIRA, F.R.; COSTA J.G. da. Melhoramento genético. In: GENÚ, P.J.de C.; PINTO, A.C. de Q. (Ed.). A cultura da mangueira. Brasília: Embrapa Informação Tecnológica, 2002a. p. 53-92.

PINTO, A.C. de Q.; COSTA J.G. da; SANTOS, C.A.F. Principais cultivares. In: GENÚ, P.J. de C.; PINTO, A.C. de Q. (Ed.). A cultura da mangueira. Brasília: Embrapa Informação Tecnológica, 2002b. p. 93-116.

SCHNELL, R.J.; BROWN, J.S.; OLANO, C.T.; MEEROW, A.W.; CAMPBELL, R.J.; KUHN, D.N. Mango genetic diversity analysis and pedigree inferences for Florida cultivars using microsatellite markers. Journal of the American Society for Horticultural Science, Athens, v. 131, n. 2, p. 214224, 2006.

SCHNELL, R.J.; OLANO, C.T.; QUINTANILLA, W.E.; MEEROW, A.W. Isolation and characterization of 15 microsatellite loci from mango (Mangifera indicaL.) and cross-species amplification in closely related taxa. Molecular Ecology Notes, Oxford, v.5, p. 625-627, 2005.

SIQUEIRA, K.M.M. de; KIILL, L.H.P.; MARTINS, C.F.; LEMOS, I.B.; MONTEIRO, S.P.; FEITOZA, E. de A. Estudo comparativo da polinização de Mangifera indica em cultivo convencional e orgânico na região do vale do submédio do São Francisco. Revista Brasileira de Fruticultura, Jaboticabal, v. 30, n. 2, p. 303-310, 2008. 